\title{
Thermodynamic equilibrium of hydroxyacetic acid in pure and binary solvent systems
}

Qiaoyin Huang ${ }^{\mathrm{a}}$, Chuang $\mathrm{Xie}^{\mathrm{a}, \mathrm{b}^{*}}$,Yang $\mathrm{Li}^{\mathrm{a}}$, Nannan $\mathrm{Su}^{\mathrm{a}}$, Yajing Lou ${ }^{\mathrm{a}}$, Xiaoxue $\mathrm{Hu}^{\mathrm{a}}$, Yongli Wang ${ }^{\mathrm{a}, \mathrm{b}^{*}}$, Ying $\mathrm{Bao}^{\mathrm{a}, \mathrm{b}}$, Baohong $\mathrm{Hou}^{\mathrm{a}, \mathrm{b}}$

${ }^{\text {a }}$ School of Chemical Engineering and Technology, Tianjin University, Tianjin 300072, China.

${ }^{\mathrm{b}}$ Collaborative Innovation Center of Chemical Science and Engineering (Tianjin), Tianjin 300072, China.

*Corresponding author. Tel.: +86-22-27405754; Fax: +86-22-27374971.

E-mail address: acxie@tju.edu.cn, yliwang@tju.edu.cn

ABSTRACT: The solubility of hydroxyacetic acid in five pure organic solvents and two binary solvent mixtures were experimentally measured from $273.15 \mathrm{~K}$ to 313.15 $\mathrm{K}$ at atmospheric pressure $(p=0.1 \mathrm{MPa})$ by using a dynamic method. The order of solubility in pure organic solvents is ethanol $>$ isopropanol $>$ n-butanol $>$ acetonitrile $>$ ethyl acetate within the investigated temperature range, except for temperature lower than $278 \mathrm{~K}$ where the solubility of HA in ethyl acetate is slightly larger than that in acetonitrile. Furthermore, the solubility data in pure solvents were correlated with the modified Apelblat model, NRTL model, and Wilson model and that in the binary solvents mixtures were fitted to the CNIBS/R-K model and Jouyban-Acree model. Finally, the mixing thermodynamic properties of hydroxyacetic acid in pure and binary solvent systems were calculated and discussed.

Keywords: Hydroxyacetic acid; Solubility; Correlation; Mixing properties 


\section{Introduction}

Hydroxyacetic acid (HA, CAS: 79-14-1, Figure 1), the smallest and simplest compound of $\alpha$-hydroxy acid family [1], is a fundamental organic compound and an important organic synthesis intermediate. HA is widely used in chemical cleaning and daily-used chemical industrial [2,3]. HA is also an important precursor to produce biodegradable materials such as polyglycolic acid and poly (lactic-co-glycolic) acid [4]. The purification of HA is usually achieved via extraction or crystallization [5]. Unfortunately, there is lack of the solubility data of HA except in water according to literatures. For aqueous solution, the extremely large aqueous solubility and gentle slope of HA solubility curve make it less efficient to produce via crystallization. So it is necessary to develop the crystallization process in other solvent systems.

In this work, the solubility of HA in five common pure solvents (ethanol, isopropanol, n-butanol, ethyl acetate, and acetonitrile) and two binary solvent mixtures (ethyl acetate + acetone and ethyl acetate + ethanol) were experimentally measured by a dynamic method from $273.15 \mathrm{~K}$ to $313.15 \mathrm{~K}$ under atmospheric pressure. The experimental data were then correlated with multiple models. Furthermore, the mixing thermodynamic properties were calculated and discussed. The results of this work would be helpful to develop and optimize a crystallization process of HA.

\section{Experimental section}

\subsection{Materials}

HA ( $\geq 99.9$ wt\%) used in this work was purchased from J\&K Scientific Co., Ltd. 
and dried before solubility measurement in a vacuum oven at $313.15 \mathrm{~K}$ for $48 \mathrm{~h}$. All the organic solvents used in this work were purchased from Jiangtian Chemical Co., Ltd., Tianjin, and used without further treatment. The distilled water was prepared in laboratory. Table 1 provides the detailed information of all the materials used in this work.

\subsection{Apparatus and methods}

The solubility experiments were conducted by a dynamic method according to the literatures [6,7]. At the beginning of experiment, the weighed HA and solvent were mixed in a $50 \mathrm{ml}$ double-jacketed glass vessel with continuous magnetic agitation at a preset temperature. The temperature was controlled by a thermostat (Xianou Laboratory Instrument Works Co., Ltd, Nanjing) with an accuracy of $\pm 0.1 \mathrm{~K}$. A laser beam penetrating the vessel was used to monitor the dissolution process. When the solute dissolved completely, the solution became clear and the intensity of excident light reached the maximum. Afterward, small amount of solute with known weight was added into the vessel. The intensity of excident light rapidly dropped down due to the solute addition and then gradually increased to the maximum when the solute dissolved completely. Such addition of small amount of solute was repeated until the intensity of excident light could not return to the maximum in $4 \mathrm{~h}$, indicating the solution was saturated. The mass of the added solute and solvent were weighed using an analytical balance (Mettler Toledo AB204-N, Switzerland) with an accuracy of $\pm 0.0001 \mathrm{~g}$. Each experiment was repeated three times, and the average was used to calculate the mole fraction solubility. 
The mole fraction solubility of HA was calculated by the following equation:

$$
x_{1}=\frac{m_{1} / M_{1}}{\left(m_{1} / M_{1}\right)+\sum m_{\mathrm{i}} / M_{\mathrm{i}}}
$$

where $x_{1}$ represents the mole fraction solubility of $\mathrm{HA} ; m_{1}$ and $m_{\mathrm{i}}$ represent the mass of HA and the solvents respectively. $M_{1}, M_{\mathrm{i}}$ are the molecular mass of HA and solvents, respectively.

\subsection{Characterization of $\mathrm{HA}$}

The HA used in the experiment was verified by powder X-ray diffraction (PXRD), which was carried out on Rigaku D/max-2500 (Rigaku, Japan). Suspension experiments in the selected solvents were carried out to identify the HA phase transformation via determining the PXRD of suspended crystals.

The melting properties of HA were determined by DSC 1/500 (Mettler Toledo, Switzerland) under protection of nitrogen gas at a heating rate of $5 \mathrm{~K} \cdot \mathrm{min}^{-1}$. The DSC instrument was calibrated by indium and zinc before determination. The standard uncertainty of temperature measurement and enthalpy of fusion measurement were $0.5 \mathrm{~K}$ and $0.5 \mathrm{~kJ} \cdot \mathrm{mol}^{-1}$ respectively.

\section{Thermodynamic models}

\subsection{The Modified Apelblat equation}

The Modified Apelblat equation in Eq. (2) is a semi-empirical model and widely used for accurate correlation of solid-liquid equilibrium data [8]:

$$
\ln x_{1}=A+B /(T / \mathrm{K})+C \ln (T / \mathrm{K})
$$

where $x_{1}$ is the solubility of HA, $T$ is the absolute temperature, and $A, B, C$ are the empirical constants of this equation. 


\subsection{The NRTL model}

According to the solid-liquid phase equilibrium theory, the fugacity of the compound in two phases should be equal when the system reaches phase equilibrium. Thus the relationship between equilibrium solubility and temperature can be expressed by Eq. (3) [9]:

$$
\ln x_{1}=\frac{\Delta_{\text {fus }} H}{R}\left(\frac{1}{T_{\mathrm{m}} / \mathrm{K}}-\frac{1}{T / \mathrm{K}}\right)-\ln \gamma_{\mathrm{i}}-\frac{1}{(R T / \mathrm{K})} \int_{T_{\mathrm{m}}}^{T} \Delta C_{\mathrm{p}} d T+\frac{1}{R} \int_{T_{\mathrm{m}}}^{T} \frac{\Delta C_{\mathrm{p}}}{T / \mathrm{K}} d T
$$

where $\Delta_{\text {fus }} H, T_{\mathrm{m}}$ and $\Delta C_{\mathrm{p}}$ refer to the enthalpy of fusion, the melting temperature of solute, and the change of the heat capacity between the melting and solid state of pure solute, respectively. $\gamma_{i}$ refers to the activity coefficient of solute. Considering the last two parts in the right hand side of Eq. (3) are less important than the first two parts due to the negligible value of $\Delta C_{\mathrm{p}}$, Eq. (3) can be simplified as [10]:

$$
\ln x_{1}=\frac{\Delta_{\text {fus }} H}{R}\left(\frac{1}{T_{\mathrm{m}} / \mathrm{K}}-\frac{1}{T / \mathrm{K}}\right)-\ln \gamma_{\mathrm{i}}
$$

To calculate Eq. (4), the activity coefficient $\gamma_{\mathrm{i}}$ should be obtained first. In this work, $\gamma_{\mathrm{i}}$ were calculated by using NRTL model and Wilson model.

NRTL model can be expressed as Eq. (5) for binary system (pure solvent) and as Eq. (6) for ternary system (binary solvent mixture) [11,12]:

$$
\ln \gamma_{\mathrm{i}}=x_{\mathrm{j}}^{2}\left[\frac{\tau_{\mathrm{ji}} G_{\mathrm{ji}}^{2}}{\left(x_{\mathrm{i}}+G_{\mathrm{ji}} x_{\mathrm{j}}\right)^{2}}+\frac{\tau_{\mathrm{ij}} G_{\mathrm{ij}}^{2}}{\left(x_{\mathrm{j}}+G_{\mathrm{ij}} x_{\mathrm{i}}\right)^{2}}\right]
$$




$$
\begin{aligned}
& \ln \gamma_{\mathrm{i}}=\frac{\left(G_{\mathrm{ji}} x_{\mathrm{j}}+G_{\mathrm{kj}} x_{\mathrm{k}}\right)\left(\tau_{\mathrm{ji}} G_{\mathrm{ji}} x_{\mathrm{j}}+\tau_{\mathrm{ki}} G_{\mathrm{ki}} x_{\mathrm{k}}\right)}{\left(x_{\mathrm{i}}+G_{\mathrm{ji}} x_{\mathrm{j}}+G_{\mathrm{ki}} x_{\mathrm{k}}\right)^{2}} \\
& +\frac{\left[\tau_{\mathrm{ij}} G_{\mathrm{ij}} x_{\mathrm{j}}^{2}+G_{\mathrm{ij}} G_{\mathrm{kj}} x_{\mathrm{j}} x_{\mathrm{k}}\left(\tau_{\mathrm{ij}}-\tau_{\mathrm{kj}}\right)\right]}{\left(x_{\mathrm{j}}+G_{\mathrm{ij}} x_{\mathrm{i}}+G_{\mathrm{kj}} x_{\mathrm{k}}\right)^{2}} \\
& +\frac{\left[\tau_{\mathrm{ik}} G_{\mathrm{ik}} x_{\mathrm{k}}^{2}+G_{\mathrm{ik}} G_{\mathrm{jk}} x_{\mathrm{j}} x_{\mathrm{k}}\left(\tau_{\mathrm{ik}}-\tau_{\mathrm{jk}}\right)\right]}{\left(x_{\mathrm{k}}+G_{\mathrm{ik}} x_{\mathrm{i}}+G_{\mathrm{jk}} x_{\mathrm{j}}\right)^{2}}
\end{aligned}
$$

where $\mathrm{i}, \mathrm{j}$, k are the component of the solution system and $G_{\mathrm{ij}}, G_{\mathrm{ji}}, G_{\mathrm{ik}}, G_{\mathrm{jk}}, G_{\mathrm{kj}}, G_{\mathrm{ki}}, \tau_{\mathrm{ij}}$, $\tau_{\mathrm{ji}}, \tau_{\mathrm{ik}}, \tau_{\mathrm{jk}}, \tau_{\mathrm{kj}}, \tau_{\mathrm{ki}}$, are parameters of this model, which could be expressed as follows:

$$
\begin{gathered}
G_{\mathrm{ij}}=\exp \left(-\alpha_{\mathrm{ij}} \tau_{\mathrm{ij}}\right) \\
\tau_{\mathrm{ij}}=\frac{\mathrm{g}_{\mathrm{ij}}-\mathrm{g}_{\mathrm{jj}}}{R T / \mathrm{K}}=\frac{\Delta g_{\mathrm{ij}}}{R T / \mathrm{K}} \\
\alpha_{\mathrm{ij}}=\alpha_{\mathrm{ji}}
\end{gathered}
$$

where $\Delta g_{\mathrm{ij}}$ is the parameter of this model and $\alpha$ is an adjustable constant between 0 and $1[13,14]$.

\subsection{Wilson model}

Wilson model can be expressed as Eq. (10) for binary system (pure solvent) [15]:

$$
\ln \gamma_{\mathrm{i}}=-\ln \left(x_{\mathrm{i}}+\Lambda_{\mathrm{ij}} x_{\mathrm{j}}\right)+x_{\mathrm{j}}\left(\frac{\Lambda_{\mathrm{ij}}}{x_{\mathrm{i}}+\Lambda_{\mathrm{ij}} x_{\mathrm{j}}}-\frac{\Lambda_{\mathrm{ji}}}{x_{\mathrm{j}}+\Lambda_{\mathrm{ji}} x_{\mathrm{i}}}\right)
$$

where,

$$
\Lambda_{\mathrm{ij}}=\frac{V_{\mathrm{j}}}{V_{\mathrm{i}}} \exp \left(-\frac{\lambda_{\mathrm{ij}}-\lambda_{\mathrm{jj}}}{R T / \mathrm{K}}\right)=\frac{V_{\mathrm{j}}}{V_{\mathrm{i}}} \exp \left(-\frac{\Delta \lambda_{\mathrm{ij}}}{R T / \mathrm{K}}\right)
$$

In Eq. (11), $V_{\mathrm{i}}$ and $V_{\mathrm{j}}$ are the mole volume of solute and solvent, respectively. $\Delta \lambda_{\mathrm{ij}}$ is the adjustable parameter of this model.

\subsection{The CNIBS/R-K model}

The CNIBS/R-K model, proposed by Acree and Zvaigzne [16,17], is suggested 
to be the most appropriate model for binary solvent mixture system. The simplified equation is shown in Eq. (12):

$$
\ln x_{1}=B_{0}+B x_{1}^{0} \frac{1}{2} B_{2}\left(x^{0}\right)_{2}^{2}+B\left(x_{3}\right)^{3} \frac{1}{2} B\left(x_{4}\right)^{0}
$$

where $x_{1}$ is the solubility of HA, $x_{2}^{0}$ stands for the initial mole fraction composition of the binary solvent system, $B_{0}-B_{4}$ are empirical model parameters.

\subsection{The Jouyban-Acree model}

The Jouyban-Acree model is also widely used to describe the solubility in binary solvent mixture system considering both composition of the solvent mixture and temperature. The model is shown as follows [18]:

$$
\begin{aligned}
& \ln x_{1}=A_{0}+A_{1} /(T / \mathrm{K})+A_{2} \ln (T / \mathrm{K})+A_{3} x_{2}^{0}+ \\
& {\left[A_{4} x_{2}^{0}+A_{5}\left(x_{2}^{0}\right)^{2}+A_{6}\left(x_{2}^{0}\right)^{3}+A_{7}\left(x_{2}^{0}\right)^{4}\right] /(T / \mathrm{K})+A_{8} x_{2}^{0} \ln (T / \mathrm{K})}
\end{aligned}
$$

where $A_{0}-A_{8}$ are empirical model parameters.

\section{Results and discussion}

\subsection{Characterization and identification of materials}

The PXRD pattern of HA used in this work is shown in Figure 2. Compared with the PXRD pattern of HA from Cambridge Crystallographic Data Centre (CCDC), the PXRD pattern of HA samples have the same peaks at $14^{\circ}, 20^{\circ}, 25^{\circ}, 30^{\circ}, 34^{\circ}, 40^{\circ}$ and so on, confirming high crystalline HA used in this work. In addition, the PXRD of solid HA obtained from suspension experiments kept unchanged, indicating that no polymorphic transformations occurred during the solid-liquid equilibrium in the selected systems. 
The melting properties of HA were measured by DSC and given in Figure 3. The melting temperature $\left(T_{\mathrm{m}}\right)$ of $\mathrm{HA}$ is $350.75 \mathrm{~K}$ and the enthalpy of fusion $\left(\Delta_{\text {fus }} H\right)$ is calculated as $19.9 \mathrm{~kJ} \cdot \mathrm{mol}^{-1}$, which are consistent with literature data $\left(T_{\mathrm{m}}=351.3 \mathrm{~K}\right.$, $\Delta_{\text {fus }} H=19.3 \mathrm{~kJ} \cdot \mathrm{mol}^{-1}$ ) [19]. The density of HA obtained from literature is $1.49 \mathrm{~g} \cdot \mathrm{cm}^{-3}$

(293.15 K) [20]. Then the mole volume of HA could be calculated to be 51.04 $\mathrm{cm}^{3} \cdot \mathrm{mol}^{-1}$, which was used for Wilson model calculation. The mole volumes of the solvents used in this work were obtained from literature [21].

\subsection{Solubility of HA in pure solvents}

The experimental solubility data of HA in pure solvents are listed in Table 2 and graphically plotted in Figure 4. It shows that the solubility in these pure solvents increases with rising temperature, indicating that the dissolution processes in all these solvents are endothermic. Within the temperature range of this work, the order of HA solubility in the tested solvents is: ethanol $>$ isopropanol $>$ n-butanol $>$ acetonitrile $>$ ethyl acetate, except for temperature lower than $278 \mathrm{~K}$ where the solubility of HA in ethyl acetate is slightly larger than that in acetonitrile. This order is consistent with the order of the polarity of the selected solvents which is ethanol > isopropanol > n-butanol > acetonitrile > ethyl acetate [16]. The solubility order of polar HA in these solvents can be explained by the principle of "like dissolve like".

The experimental solubility data in pure solvents were correlated by the Modified Apelblat model, NRTL model and Wilson model. The calculated results and related parameters are listed in Table 2 and Table 3, respectively. The average relative deviation percentage $(A R D P)$ and root-mean-square $(R M S D)$, which are defined in Eq. 
(14) and Eq. (15), were introduced to evaluate the precision of these models.

$$
\begin{gathered}
A R D P=\frac{1}{N} \sum_{i=1}^{N}\left|\frac{\left(x_{\mathrm{i}}^{\mathrm{cal}}-x_{\mathrm{i}}^{\mathrm{exp}}\right)}{x_{\mathrm{i}}^{\exp }}\right| \\
R M S D=\left(\frac{\sum_{i=1}^{N}\left(x_{\mathrm{i}}^{\mathrm{cal}}-x_{\mathrm{i}}^{\exp }\right)^{2}}{N}\right)^{1 / 2}
\end{gathered}
$$

where $N$ stands for the number of the experimental points, $x_{1}^{\exp }$ and $x_{1}^{\text {cal }}$ refer to the experimental and calculated mole fraction solubility of HA, respectively. The values of $A R D P$ and $R M S D$ are also listed in Table 3.

According to Table 3, the ARDP results of these three models are all less than 5\%, and the $10^{3} R M S D$ results of these models are less than 10 , which indicate that all these models can correlate the experimental data precisely.

\subsection{Solubility of HA in binary solvent mixtures}

The experimental solubilities of HA in two binary solvent mixtures (ethanol + ethyl acetate and acetone + ethyl acetate) at $273.15 \mathrm{~K}$ to $313.15 \mathrm{~K}$ are listed in Table 4 and Table 5 and plotted in Figure 5, Figure 6 and Figure 7. The solubility of HA in all the investigated solvent mixtures increases with rising temperature, and increases with decreasing mole fraction of ethyl acetate at a fixed temperature.

The CNIBS/R-K model and Jouyban-Acree model were used to correlate the experimental data in binary solvent mixture. The correlation results are also listed in Table 4 and Table 5. ARDP, $R^{2}$, and related parameters of the two models are given in Table 6 and Table 7. According to the Table 6 and Table 7, the $R^{2}$ values for these two models are higher than $0.99, A R D P$ are lower than $2 \%$ and $10^{3} R M S D$ are all lower than 5. These results reveal that both the CNIBS/R-K model and the Jouyban-Acree 
model correlate the experimental data precisely.

\subsection{The mixing thermodynamic properties}

The mixing properties, such as mixing Gibbs energy $\Delta G_{\text {mix }}$, mixing enthalpy $\Delta S_{\text {mix }}$, and mixing entropy $\Delta H_{\text {mix }}$, in pure solvents and binary solvent mixtures were calculated according to Eq. (16) - (18) [22]:

$$
\begin{gathered}
\Delta G_{\text {mix }}=G^{\mathrm{E}}+\Delta G^{\text {id }} \\
\Delta S_{\text {mix }}=S^{\mathrm{E}}+\Delta S^{\text {id }} \\
\Delta H_{\text {mix }}=H^{\mathrm{E}}+\Delta H^{\text {id }}
\end{gathered}
$$

where $\Delta G^{\text {id }}, \Delta S^{\text {id }}$ and $\Delta H^{\text {id }}$ are the mixing properties of an ideal solution, and $G^{\mathrm{E}}, S^{\mathrm{E}}$ and $H^{\mathrm{E}}$ refer to the excess properties of the real solution. For ideal solution,

$$
\begin{gathered}
\Delta G^{\mathrm{id}}=R(T / \mathrm{K}) \sum_{\mathrm{i}}^{\mathrm{n}} x_{\mathrm{i}} \ln x_{\mathrm{i}} \\
\Delta S^{\mathrm{id}}=-\frac{\Delta G^{\mathrm{id}}}{(T / \mathrm{K})} \\
\Delta H^{\mathrm{id}}=0
\end{gathered}
$$

where $x_{\mathrm{i}}$ represents the mole fraction of each component in solution. $n$ takes 2 for binary component (pure solvent), and takes 3 for ternary component (binary solvent system).

For non-ideal solution, the excess mixing properties could be first calculated by the following equations:

$$
\begin{gathered}
G^{\mathrm{E}}=R(T / \mathrm{K}) \sum_{\mathrm{i}}^{\mathrm{n}} x_{\mathrm{i}} \ln \gamma_{\mathrm{i}} \\
H^{\mathrm{E}}=-R(T / \mathrm{K})^{2} \sum_{\mathrm{i}}^{\mathrm{n}} x_{\mathrm{i}}\left(\frac{\partial \ln \gamma_{\mathrm{i}}}{\partial T}\right)_{p, x}
\end{gathered}
$$




$$
S^{\mathrm{E}}=\frac{H^{\mathrm{E}}-G^{\mathrm{E}}}{(T / \mathrm{K})}
$$

where $\gamma_{\mathrm{i}}$ refers to the activity coefficient of component $i$ in non-ideal solution, which can be calculated by NRTL model (Eq. (5) and (6)).

Since the binary solvent systems are pre-mixed before the dissolution of HA, the mixing properties of solvent mixing process should be excluded first. The ideal and excess thermodynamic properties of pre-mixed solvents were calculated by using Eq. (19)-(24). Then the mixing properties of pre-mixed solvents were obtained and subtracted from the mixing properties of solute-solvent system. The calculated mixing thermodynamic properties in the five pure solvents are listed in Table 8 while the mixing thermodynamic properties excluding the pre-mixing in binary solvent mixtures are listed in Table 9 and Table 10. The mixing Gibbs energy $\Delta G_{\text {mix }}$ in both pure and binary solvent system are all negative, which also decrease with increasing temperature. It indicates that the dissolution processes of HA in all these solvent systems are spontaneous. The positive mixing enthalpy $\Delta S_{\text {mix }}$ in all the selected solvent systems indicates that the dissolution processes of $\mathrm{HA}$ in these solvent systems are entropy-driven [23].

\section{Conclusions}

In this work, the solubility of HA in five pure solvents and two binary solvent mixtures were experimentally measured from $T=(273.15 \mathrm{~K}$ to 313.15$) \mathrm{K}$ at atmospheric pressure by a dynamic method. The solubility of HA in the selected pure solvents increases with increasing temperature. Within the temperature range of this work, the solubility order of HA in the tested pure solvents is: ethanol > isopropanol > 
n-butanol > acetonitrile > ethyl acetate, which is consistent with the polarity order of the selected solvents. The solubility data in the five pure solvents could be accurately correlated by the Modified Apelblat model, NRTL model, and Wilson model in the selected pure solvents, while the CNIBS/R-K model and the Jouyban-Acree model can fit the data in the tested two binary solvent mixtures with high accuracy. The calculation results of the mixing properties of HA in both pure and binary solvent mixtures revealed that the dissolution process of HA in all the selected solvent systems are spontaneous and entropy-driven.

\section{Acknowledgement}

The authors thank the National Science Foundation of China (No. 21576187) and the Major National Scientific Instrument Development Project (No. 21527812) for the financial support.

\section{References}

[1] D. Datta, S. Kumar, Ind. Eng. Chem. Res. 50 (2011) 3041-3048.

[2] C.M. Ditre, T.D. Griffin, G.F. Murphy, H. Sueki, B. Telegan, W.C. Johnson, J.Y. Ruey, E.J. Van Scott, J. Am. Acad. Dermatol. 34 (1996) 187-195.

[3] C. Cotellessa, K. Peris, S. Chimenti, J. Eur. Acad. Dermatol. Venereol. 5 (1995) 
215-217.

[4] S. Suzuki, K. Yamane, T. Ono, K. Sunagawa, US Patent NO.8722907B2, 2014.

[5] Y. Shi, H. Sun, D. Lu, Q. Le, D. Chen, Y. Zhou. Sep. Purif. Technol. 49 (2006) $20-26$

[6] H. Hao, J. Wang, Y. Wang, J. Chem. Eng. Data 49 (2004) 1697-1698.

[7] Q. Chen, Y. Wang, X. Wu, J. Wang, J. Chem. Eng. Data 53 (2008) 1414-1416.

[8] A. Apelblat, E. Manzurola, J. Chem. Thermodyn. 31 (1999) 85-91.

[9] J. Xu, Y. Wang, G. Wang, C. Huang, H. Hao, Q. Yin, J. Chem. Thermodyn. 92 (2016) 12-20.

[10] H. Buchowski, A. Ksiazczak, S. Pietrzyk, J. Phys. Chem. 84 (1980) 975-979.

[11] J. Ouyang, J. Wang, H. Hao, X. Huang, Y. Gao, Y. Bao, Y. Wang, Q. Yin, Fluid Phase Equilib. 372 (2014) 7-14.

[12] H. Renon, J.M. Prausnitz, AIChE journal 14 (1968) 135-144.

[13] Z. Teng, Z. Li, W. Yan, L. Cong, Y. Bo, X. Zheng, J. Lei, J. Gong, J. Chem. Thermodyn. 96 (2015) 82-92.

[14] D. Wei, Y. Pei, Ind. Eng. Chem. Res. 47 (2008) 8953-8956.

[15] J. Wang, C. Xie, Q. Yin, L. Tao, J. Lv, Y. Wang, F. He, H. Hao, J. Chem. Thermodyn. 95 (2016) 63-71.

[16] H. Wang, Y. Wang, G. Wang, J. Zhang, H. Hao, Q. Yin, Fluid Phase Equilib. 382 (2014) 197-204.

[17] W.E. Acree, Thermochimica Acta 198 (1992) 71-79.

[18] M. Barzegar-Jalali, A. Jouyban-Gharamaleki, Int. J. Pharm. 152 (1997) 247-250. 
[19] V. N. Emel'yanenko, S.P. Verevkin, E.N. Stepurko, G.N. Roganov, M.K. Georgieva, Russ. J. Phys. Chem. 84 (2010) 1301-1308.

[20] Ullmann's Encyclopedia of Industrial Chemistry, fifth edition, VCH Publishers, 1985.

[21] D. R. Lide, CRC Handbook of Chemistry and Physics, CRC press, 2004.

[22] S. Du, Y. Wang, J. Li, S. Wu, W. Dun, X. Song, J. Wang, J. Gong, J. Chem. Thermodyn. 93 (2016) 132-142.

[23] M. Sheikhzadeh, S. Rohani, M. Taffish, S. Murad, Int. J. Pharm. 338 (2007) $55-63$. 


\section{Figure captions:}

Figure 1. The chemical structure of HA.

Figure 2. The PXRD pattern of HA crystals.

Figure 3. Thermal analysis (DSC) of HA.

Figure 4. Experimental and calculated solubility of HA in different pure solvents form $273.15 \mathrm{~K}$ to $313.15 \mathrm{~K}(p=0.1 \mathrm{MPa})$ : $\boldsymbol{\square}$, ethyl acetate; $\boldsymbol{\Delta}$, n-butanol; $\boldsymbol{\nabla}$, isopropanol; $\diamond$, ethanol; $\boldsymbol{\bullet}$, acetonitrile. Solid lines are correlated by the Modified Apelblat model.

Figure 5. Mole fraction solubility $\left(x_{1}\right)$ of HA in binary \{ethanol + ethyl acetate solvent mixtures at different mole fraction of ethanol: $\mathbf{\square}, 273.15 \mathrm{~K} ; \bullet, 278.15 \mathrm{~K}$; ○, 283.15 K; $\boldsymbol{\Delta}, 288.15 \mathrm{~K} ; \boldsymbol{\nabla}, 293.15 \mathrm{~K} ; \boldsymbol{\nabla}, 298.15 \mathrm{~K} ; \boldsymbol{4}, 303.15 \mathrm{~K} ; \bullet, 308.15 \mathrm{~K}$; $\star, 313.15 \mathrm{~K}$. The solid lines are correlated data from CNIBS/R-K model.

Figure 6. Mole fraction solubility $\left(x_{1}\right)$ of HA in binary \{acetone + ethyl acetate $\}$ solvent mixture at different mole fraction of acetone: $\mathbf{\square}, 273.15 \mathrm{~K} ; \bullet, 278.15 \mathrm{~K}$; •, $283.15 \mathrm{~K} ; \boldsymbol{\Delta}, 288.15 \mathrm{~K} ; \boldsymbol{\nabla}, 293.15 \mathrm{~K} ; \boldsymbol{\nabla}, 298.15 \mathrm{~K} ; \triangleleft, 303.15 \mathrm{~K} ; \star \star 308.15 \mathrm{~K}$; - $313.15 \mathrm{~K}$. The solid line are correlated data from CNIBS/R-K model.

Figure 7. 3-dimension plot of solubility in two binary solvent mixtures: (a), ethanol + ethyl acetate; (b), acetone + ethyl acetate. 


\section{Table Headings:}

TABLE 1. Description of chemicals used in this work.

TABLE 2. Experimental mole solubility, $x_{1}^{\text {exp }}$, and calculated mole solubility, $x_{1}^{\text {cal }}$, of HA in pure solvents from $273.15 \mathrm{~K}$ to $313.15 \mathrm{~K}(p=0.1 \mathrm{MPa})$.

TABLE 3. Parameters of Modified Apeblat, NRTL model and Wilson models in pure solvents.

TABLE 4. Experimental mole fraction solubility, $x_{1}^{\exp }$, and calculated mole fraction solubility, $x_{1}^{\text {cal }}$, of crystalline HA in binary solvent mixture \{ethanol (2) + ethyl acetate (3) $\}$ from $273.15 \mathrm{~K}$ to $313.15 \mathrm{~K}(p=0.1 \mathrm{MPa})$.

TABLE 5. Experimental mole fraction solubility, $x_{1}^{\text {exp }}$, and calculated mole fraction solubility, $x_{1}^{\text {cal }}$, of crystalline HA in binary solvent mixture \{acetone (2) + ethyl acetate (3) $\}$ from $273.15 \mathrm{~K}$ to $313.15 \mathrm{~K}(p=0.1 \mathrm{MPa})$.

TABLE 6. Parameters of the CNIBS/R-K model for the solubility of HA in binary solvent mixture.

TABLE 7. Parameters of the Jouyban-Acree model for the solubility of HA in binary solvent mixture.

TABLE 8. The mixing thermodynamic properties of HA in pure solvents.

TABLE 9. The mixing thermodynamic properties of HA in binary solvent mixture \{ethanol (2) + ethyl acetate (3)\}.

TABLE 10. The mixing thermodynamic properties of HA in binary solvent mixture $\{$ acetone $(2)+$ ethyl acetate (3) $\}$. 


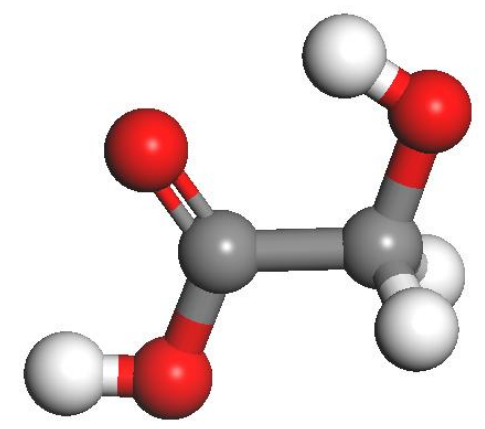

Figure 1. The chemical structure of HA.

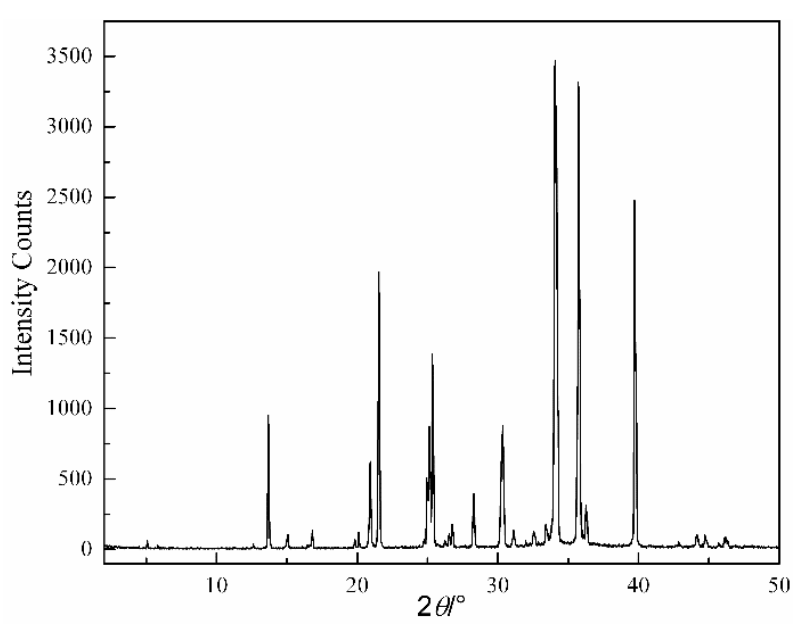

Figure 2. The PXRD pattern of HA crystals.

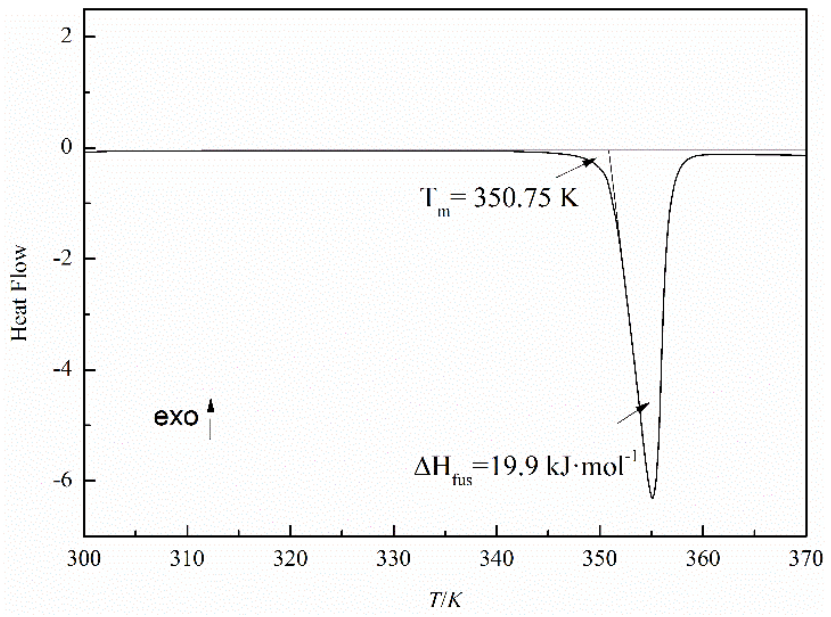

Figure 3. Thermal analysis (DSC) of HA. 


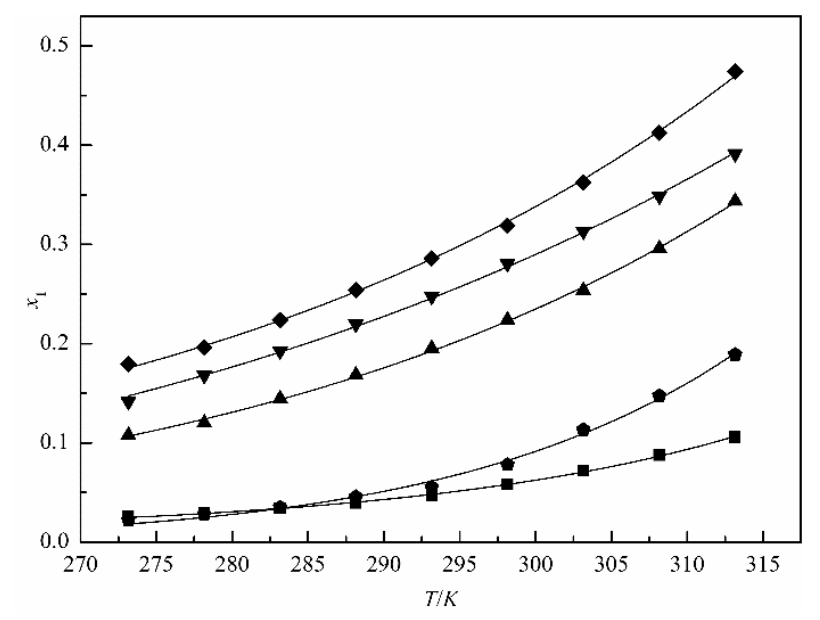

Figure 4. Experimental and calculated solubility of HA in different pure solvents form $273.15 \mathrm{~K}$ to $313.15 \mathrm{~K}(p=0.1 \mathrm{MPa})$ : $\boldsymbol{\square}$, ethyl acetate; $\boldsymbol{\Delta}$, n-butanol; $\boldsymbol{\nabla}$, isopropanol; $\diamond$, ethanol; $\bigcirc$, acetonitrile. Solid lines are correlated by the Modified Apelblat model.

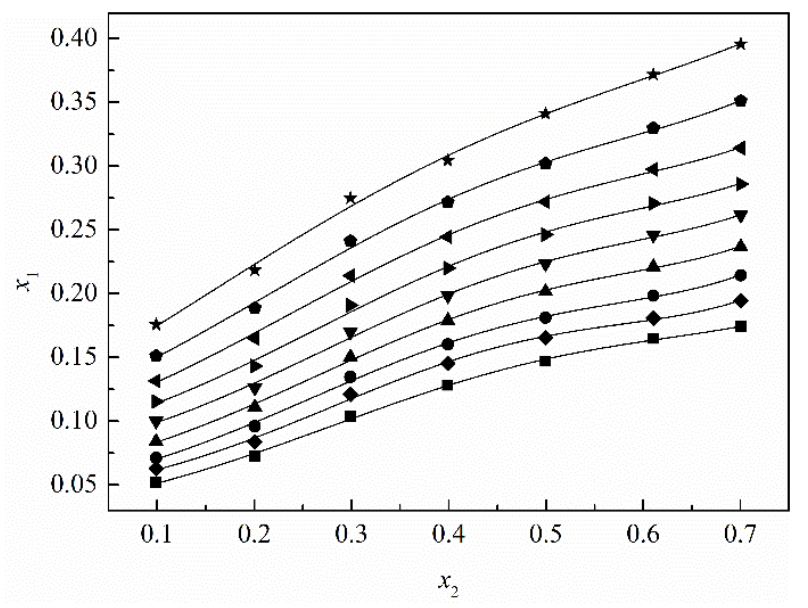

Figure 5. Mole fraction solubility $\left(x_{1}\right)$ of HA in binary $\{$ ethanol + ethyl acetate solvent mixtures at different mole fraction of ethanol: $\mathbf{\square}, 273.15 \mathrm{~K} ; \bullet, 278.15 \mathrm{~K}$; •, $283.15 \mathrm{~K} ; \boldsymbol{\Delta}, 288.15 \mathrm{~K} ; \boldsymbol{\nabla}, 293.15 \mathrm{~K} ; \boldsymbol{\nabla}, 298.15 \mathrm{~K} ; \boldsymbol{4}, 303.15 \mathrm{~K} ; \bullet, 308.15 \mathrm{~K}$; $\star$, $313.15 \mathrm{~K}$. The solid lines are correlated data from CNIBS/R-K model. 


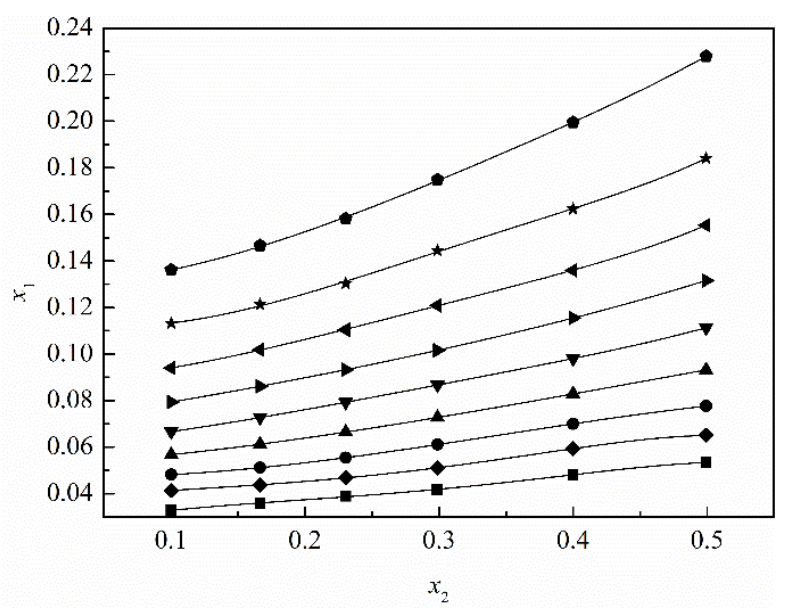

Figure 6. Mole fraction solubility $\left(x_{1}\right)$ of HA in binary \{acetone + ethyl acetate solvent mixtures at different mole fraction of acetone: $\mathbf{\square}, 273.15 \mathrm{~K} ; \bullet, 278.15 \mathrm{~K}$; •, $283.15 \mathrm{~K} ; \boldsymbol{\Delta}, 288.15 \mathrm{~K} ; \boldsymbol{\nabla}, 293.15 \mathrm{~K} ; \mathbf{\nabla}, 298.15 \mathrm{~K} ; \boldsymbol{4}, 303.15 \mathrm{~K} ; \star \star 308.15 \mathrm{~K}$;

- $313.15 \mathrm{~K}$. The solid line are correlated data from CNIBS/R-K model.

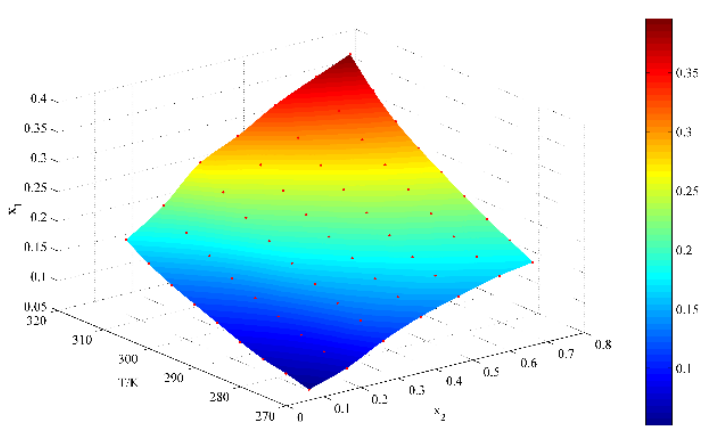

(a). ethanol + ethyl acetate

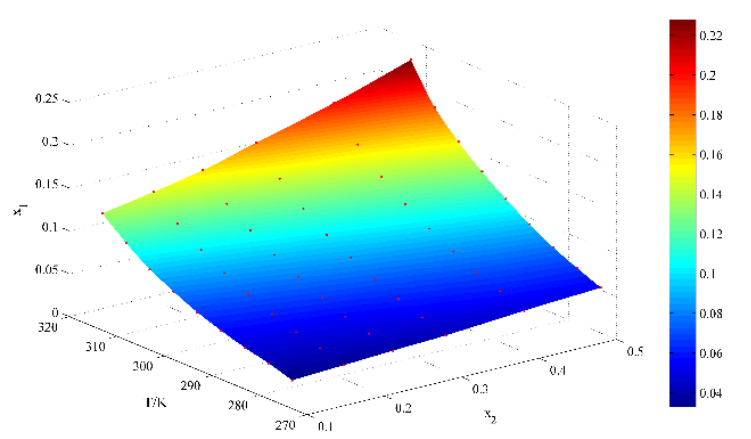


(b). acetone + ethyl acetate

Figure 7. 3-dimension plot of solubility in two binary solvent mixtures: (a), ethanol + ethyl acetate; (b), acetone + ethyl acetate. 


\section{TABLE 1}

Description of chemicals used in this work

\begin{tabular}{ccc}
\hline Material & $\begin{array}{c}\text { Mass fraction } \\
\text { Purity }^{a}\end{array}$ & Water content $^{b}$ \\
\hline hydroxyacetic & $\geq 99.9 \%$ & No measured \\
acid & $\geq 99.5 \%$ & $\leq 0.05 \%$ \\
acetonitrile & $\geq 99.7 \%$ & $\leq 0.3 \%$ \\
ethanol & $\geq 99.5 \%$ & $\leq 0.1 \%$ \\
ethyl acetate & $\geq 99.5 \%$ & $\leq 0.2 \%$ \\
n-butanol & $\geq 99.7 \%$ & $\leq 0.2 \%$ \\
isopropanol & $\geq 99.5 \%$ & $\leq 0.3 \%$ \\
acetone &
\end{tabular}

${ }^{a}$ The mass fraction purity of HA and all solvents are provided by the suppliers.

${ }^{b}$ Water content is the water mass fraction of the solvent, and is provided by the suppliers. 


\section{TABLE 2}

Experimental mole fraction solubility, $x_{1}^{\text {exp }}$, and calculated mole fraction solubility, $x_{1}^{\text {cal }}$, of crystalline HA in pure solvents from $273.15 \mathrm{~K}$ to $313.15 \mathrm{~K}$ ( $\left.p=0.1 \mathrm{MPa}\right) .{ }^{a, b}$

\begin{tabular}{|c|c|c|c|c|}
\hline$T / \mathrm{K}$ & $10^{2} x_{1}^{\exp }$ & $10^{2} x_{1}^{\text {cal }, \mathrm{A}}$ & $10^{2} x_{1}^{\text {cal, } \mathrm{N}}$ & $10^{2} x_{1}^{\text {cal,w }}$ \\
\hline \multicolumn{5}{|c|}{ ethyl acetate } \\
\hline 273.15 & 2.56 & 2.49 & 2.14 & 2.28 \\
\hline 278.15 & 2.89 & 2.90 & 2.61 & 2.76 \\
\hline 283.15 & 3.43 & 3.40 & 3.19 & 3.37 \\
\hline 288.15 & 3.95 & 4.03 & 3.87 & 4.05 \\
\hline 293.15 & 4.72 & 4.83 & 4.73 & 4.90 \\
\hline 298.15 & 5.80 & 5.82 & 5.82 & 5.93 \\
\hline 303.15 & 7.18 & 7.08 & 7.19 & 7.20 \\
\hline 308.15 & 8.77 & 8.67 & 8.89 & 8.72 \\
\hline 313.15 & 10.6 & $\begin{array}{l}10.7 \\
\text { ethan }\end{array}$ & 11.0 & 10.5 \\
\hline 273.15 & 17.9 & 17.9 & 16.9 & 17.2 \\
\hline 278.15 & 19.7 & 19.9 & 19.5 & 19.7 \\
\hline 283.15 & 22.4 & 22.3 & 22.3 & 22.5 \\
\hline 288.15 & 25.4 & 25.1 & 25.5 & 25.5 \\
\hline 293.15 & 28.6 & 28.3 & 28.9 & 28.9 \\
\hline 298.15 & 31.9 & 32.1 & 32.8 & 32.7 \\
\hline 303.15 & 36.3 & 36.4 & 36.9 & 36.7 \\
\hline 308.15 & 41.3 & 41.4 & 41.4 & 41.2 \\
\hline 313.15 & 47.4 & $\begin{array}{l}47.2 \\
\text { n-buta }\end{array}$ & 46.2 & 46.0 \\
\hline 273.15 & 10.8 & 10.7 & 10.7 & 10.4 \\
\hline 278.15 & 12.0 & 12.4 & 12.4 & 12.3 \\
\hline 283.15 & 14.5 & 14.4 & 14.4 & 14.3 \\
\hline 288.15 & 16.8 & 16.7 & 16.7 & 16.7 \\
\hline 293.15 & 19.5 & 19.3 & 19.3 & 19.4 \\
\hline 298.15 & 22.4 & 22.3 & 22.3 & 22.4 \\
\hline 303.15 & 25.4 & 25.7 & 25.6 & 25.8 \\
\hline 308.15 & 29.6 & 29.7 & 29.6 & 29.7 \\
\hline 313.15 & 34.4 & $\begin{array}{l}34.2 \\
\text { isoprop }\end{array}$ & 34.3 & 34.1 \\
\hline 273.15 & 14.2 & 14.4 & 14.8 & 14.5 \\
\hline 278.15 & 16.8 & 16.7 & 16.9 & 16.7 \\
\hline 283.15 & 19.3 & 19.1 & 19.2 & 19.1 \\
\hline
\end{tabular}




\begin{tabular}{lllll}
\hline 288.15 & 22.0 & 21.9 & 21.7 & 21.7 \\
293.15 & 24.8 & 24.8 & 24.6 & 24.7 \\
298.15 & 28.0 & 28.0 & 27.7 & 27.9 \\
303.15 & 31.3 & 31.4 & 31.2 & 31.3 \\
308.15 & 34.8 & 35.1 & 35.1 & 35.2 \\
313.15 & 39.1 & 39.0 & 39.4 & 39.3 \\
& \multicolumn{4}{c}{ acetonitrile } \\
273.15 & 2.26 & 2.01 & 2.56 & 2.22 \\
278.15 & 2.82 & 2.64 & 3.11 & 2.83 \\
283.15 & 3.51 & 3.49 & 3.78 & 3.58 \\
288.15 & 4.57 & 4.62 & 4.71 & 4.61 \\
293.15 & 5.54 & 6.13 & 5.77 & 5.81 \\
298.15 & 7.81 & 8.14 & 7.65 & 7.83 \\
303.15 & 11.3 & 10.8 & 10.7 & 10.9 \\
308.15 & 14.7 & 14.4 & 14.4 & 14.5 \\
313.15 & 18.9 & 19.2 & 19.4 & 19.2 \\
\hline
\end{tabular}

${ }^{a} x_{1}^{\text {exp }}$ represent the experimental solubility of $\mathrm{HA}, x_{1}^{\mathrm{cal}, \mathrm{A}}, x_{1}^{\mathrm{cal}, \mathrm{N}}, x_{1}^{\mathrm{cal}, \mathrm{W}}$ represent the calculated solubility by the Modified Apelblat equation, the NRTL model and the Wilson model, respectively.

${ }^{b}$ The standard uncertainty are $u(T)=0.06 \mathrm{~K}, u(p)=6 \mathrm{kPa}$. The relative standard uncertainties $u$ is $u_{\mathrm{r}}\left(x_{1}\right)=0.05$. 


\section{TABLE 3}

Parameters of Modified Apeblat, NRTL model and Wilson models in pure solvents

\begin{tabular}{ccccccc}
\hline Models & Parameters & EA $^{a}$ & Ethanol & n-butanol & Isopropanol & acetonitrile \\
\hline \multirow{4}{*}{ Modified } & $A^{b}$ & -324.1 & -162.0 & -81.01 & 40.80 & -241.1 \\
Apelblat & $10^{-2} B^{b}$ & 114.0 & 52.68 & 13.54 & -36.57 & 63.21 \\
& $C^{b}$ & 49.67 & 25.14 & 13.16 & -5.231 & 38.15 \\
& $A R D P \%^{c}$ & 1.268 & 0.6363 & 1.071 & 0.6088 & 4.696 \\
& $10^{3} R M S D^{d}$ & 0.7474 & 1.996 & 2.195 & 1.503 & 3.368 \\
& $10^{-3} \Delta g_{12}{ }^{e}$ & 5.617 & -3.091 & 16.40 & 6.288 & -16.86 \\
NRTL & $10^{-3} \Delta g_{21}{ }^{e}$ & 3.495 & 3.891 & -12.772 & -3.400 & 26.26 \\
& $A R D P \%^{c}$ & 4.512 & 1.708 & 0.957 & 1.146 & 5.687 \\
& $10^{3} R M S D^{d}$ & 2.269 & 6.512 & 1.942 & 2.977 & 3.513 \\
& $10^{-3} \Delta \lambda_{12}{ }^{f}$ & 3.660 & 6.048 & 0.023 & -1.442 & 4.533 \\
Wilson & $10^{-3} \Delta \lambda_{21}{ }^{f}$ & 12.97 & -2.882 & 4.375 & 39.69 & 0.321 \\
& $A R D P \%^{c}$ & 3.022 & 1.497 & 1.164 & 0.851 & 1.914 \\
& $10^{3} R M S D^{d}$ & 1.353 & 6.401 & 2.457 & 2.072 & 2.181 \\
\hline
\end{tabular}

${ }^{a}$ EA represents ethyl acetate.

${ }^{b} A, B$ and $C$ are the parameters of the Modified Apelblat equation.

${ }^{c} A R D P \%$ is the average relative deviation percentage calculated by Eq (14).

${ }^{d} R M S D$ is the the root-mean-square deviation calculated by Eq (15).

${ }^{e} \Delta g_{12}$ and $\Delta g_{21}$ are the parameters of the NRTL model.

${ }^{f} \Delta \lambda_{12}$ and $\Delta \lambda_{21}$ are the parameters of the Wilson model. 
TABLE 4

Experimental mole fraction solubility, $x_{1}^{\text {exp }}$, and calculated mole fraction solubility, $x_{1}^{\text {cal }}$, of crystalline HA in binary solvent mixture \{ethanol (2) + ethyl acetate (3) $\}$ from $273.15 \mathrm{~K}$ to $313.15 \mathrm{~K}(p=0.1 \mathrm{MPa})^{a, b}$

\begin{tabular}{|c|c|c|c|c|}
\hline$T / K$ & $x_{2}^{0}$ & $10^{2} x_{1}^{\exp }$ & $10^{2} x_{1}^{\mathrm{cal}, \mathrm{R}}$ & $10^{2} x_{1}^{\mathrm{cal}, \mathrm{J}}$ \\
\hline 273.15 & 0.099 & 5.20 & 5.11 & 5.72 \\
\hline 273.15 & 0.201 & 7.25 & 7.48 & 7.88 \\
\hline 273.15 & 0.299 & 10.3 & 10.2 & 10.3 \\
\hline 273.15 & 0.399 & 12.8 & 12.8 & 12.7 \\
\hline 273.15 & 0.499 & 14.7 & 14.9 & 14.7 \\
\hline 273.15 & 0.610 & 16.5 & 16.4 & 16.4 \\
\hline 273.15 & 0.700 & 17.4 & 17.4 & 18.1 \\
\hline 278.15 & 0.099 & 6.29 & 6.18 & 6.55 \\
\hline 278.15 & 0.201 & 8.36 & 8.69 & 8.93 \\
\hline 278.15 & 0.299 & 12.1 & 11.7 & 11.6 \\
\hline 278.15 & 0.399 & 14.5 & 14.6 & 14.1 \\
\hline 278.15 & 0.499 & 16.5 & 16.7 & 16.2 \\
\hline 278.15 & 0.610 & 18.1 & 18.0 & 18.0 \\
\hline 278.15 & 0.700 & 19.5 & 19.5 & 19.7 \\
\hline 283.15 & 0.099 & 7.11 & 7.02 & 7.50 \\
\hline 283.15 & 0.201 & 9.61 & 9.91 & 10.1 \\
\hline 283.15 & 0.299 & 13.5 & 13.1 & 13.0 \\
\hline 283.15 & 0.399 & 16.0 & 16.1 & 15.8 \\
\hline 283.15 & 0.499 & 18.1 & 18.2 & 18.0 \\
\hline 283.15 & 0.610 & 19.8 & 19.7 & 19.8 \\
\hline 283.15 & 0.700 & 21.4 & 21.5 & 21.6 \\
\hline 288.15 & 0.099 & 8.41 & 8.33 & 8.60 \\
\hline 288.15 & 0.201 & 11.1 & 11.4 & 11.5 \\
\hline 288.15 & 0.299 & 15.0 & 14.8 & 14.6 \\
\hline 288.15 & 0.399 & 17.9 & 17.9 & 17.6 \\
\hline 288.15 & 0.499 & 20.2 & 20.3 & 19.9 \\
\hline 288.15 & 0.610 & 22.1 & 22.0 & 21.9 \\
\hline 288.15 & 0.700 & 23.7 & 23.7 & 23.7 \\
\hline 293.15 & 0.099 & 9.99 & 9.88 & 9.86 \\
\hline 293.15 & 0.201 & 12.6 & 13.0 & 13.1 \\
\hline 293.15 & 0.299 & 17.0 & 16.5 & 16.5 \\
\hline 293.15 & 0.399 & 19.8 & 19.9 & 19.7 \\
\hline 293.15 & 0.499 & 22.3 & 22.5 & 22.2 \\
\hline 293.15 & 0.610 & 24.6 & 24.4 & 24.2 \\
\hline
\end{tabular}




\begin{tabular}{|c|c|c|c|c|}
\hline 293.15 & 0.700 & 26.1 & 26.2 & 26.0 \\
\hline 298.15 & 0.099 & 11.5 & 11.4 & 11.3 \\
\hline 298.15 & 0.201 & 14.3 & 14.8 & 14.8 \\
\hline 298.15 & 0.299 & 19.1 & 18.6 & 18.6 \\
\hline 298.15 & 0.399 & 22.0 & 22.1 & 22.1 \\
\hline 298.15 & 0.499 & 24.6 & 24.8 & 24.7 \\
\hline 298.15 & 0.610 & 27.1 & 26.9 & 26.8 \\
\hline 298.15 & 0.700 & 28.6 & 28.6 & 28.7 \\
\hline 303.15 & 0.099 & 13.2 & 13.0 & 12.9 \\
\hline 303.15 & 0.201 & 16.5 & 16.9 & 16.9 \\
\hline 303.15 & 0.299 & 21.4 & 20.9 & 21.0 \\
\hline 303.15 & 0.399 & 24.5 & 24.6 & 24.8 \\
\hline 303.15 & 0.499 & 27.2 & 27.4 & 27.6 \\
\hline 303.15 & 0.610 & 29.7 & 29.6 & 29.7 \\
\hline 303.15 & 0.700 & 31.4 & 31.5 & 31.7 \\
\hline 308.15 & 0.099 & 15.1 & 15.0 & 14.8 \\
\hline 308.15 & 0.201 & 18.9 & 19.3 & 19.2 \\
\hline 308.15 & 0.299 & 24.1 & 23.6 & 23.7 \\
\hline 308.15 & 0.399 & 27.2 & 27.4 & 27.8 \\
\hline 308.15 & 0.499 & 30.2 & 30.3 & 30.8 \\
\hline 308.15 & 0.610 & 33.0 & 32.8 & 33.1 \\
\hline 308.15 & 0.700 & 35.1 & 35.1 & 35.1 \\
\hline 313.15 & 0.099 & 17.6 & 17.4 & 17.0 \\
\hline 313.15 & 0.201 & 21.8 & 22.3 & 21.8 \\
\hline 313.15 & 0.299 & 27.5 & 26.8 & 26.8 \\
\hline 313.15 & 0.399 & 30.4 & 30.8 & 31.3 \\
\hline 313.15 & 0.499 & 34.1 & 34.1 & 34.5 \\
\hline 313.15 & 0.610 & 37.2 & 37.1 & 36.8 \\
\hline 313.15 & 0.700 & 39.6 & 39.6 & 39.0 \\
\hline
\end{tabular}

${ }^{a} x_{1}^{\mathrm{cal}, \mathrm{R}}, x_{1}^{\mathrm{cal}, \mathrm{J}}$ represent the calculated solubility of HA by the CNIBS/R-K and the Jouban-Acree models, respectively. And $x_{2}^{0}$ is the initial mole fraction composition of ethanol in the binary solvent mixture.

${ }^{b}$ The standard uncertainty are $u(T)=0.06 \mathrm{~K}, u(p)=6 \mathrm{kPa}$, the relative standard uncertainties is $u_{\mathrm{r}}\left(x_{1}\right)=0.05, u_{\mathrm{r}}\left(x_{2}^{0}\right)=0.02$. 


\section{TABLE 5}

Experimental mole fraction solubility, $x_{1}^{\text {exp }}$, and calculated mole fraction solubility, $x_{1}^{\text {cal }}$, of crystalline HA in binary solvent mixture \{acetone (2) + ethyl acetate (3) $\}$ from 273.15 K to $313.15 \mathrm{~K}(p=0.1 \mathrm{MPa})^{a, b}$

\begin{tabular}{ccccc}
\hline$T / K$ & $x_{2}^{0}$ & $10^{2} x_{1}^{\text {exp }}$ & $10^{2} x_{1}^{\text {cal, R }}$ & $10^{2} x_{1}^{\text {cal,J }}$ \\
\hline 273.15 & 0.100 & 3.29 & 3.29 & 3.43 \\
273.15 & 0.166 & 3.59 & 3.61 & 3.67 \\
273.15 & 0.230 & 3.89 & 3.87 & 3.98 \\
273.15 & 0.299 & 4.18 & 4.19 & 4.35 \\
273.15 & 0.400 & 4.82 & 4.82 & 4.92 \\
273.15 & 0.499 & 5.34 & 5.34 & 5.56 \\
278.15 & 0.100 & 4.14 & 4.14 & 4.05 \\
278.15 & 0.166 & 4.38 & 4.39 & 4.33 \\
278.15 & 0.230 & 4.69 & 4.68 & 4.69 \\
278.15 & 0.299 & 5.11 & 5.12 & 5.13 \\
278.15 & 0.400 & 5.94 & 5.94 & 5.80 \\
278.15 & 0.499 & 6.51 & 6.51 & 6.56 \\
283.15 & 0.100 & 4.82 & 4.82 & 4.78 \\
283.15 & 0.166 & 5.13 & 5.12 & 5.12 \\
283.15 & 0.230 & 5.54 & 5.55 & 5.55 \\
283.15 & 0.299 & 6.12 & 6.11 & 6.06 \\
283.15 & 0.400 & 7.00 & 7.00 & 6.86 \\
283.15 & 0.499 & 7.77 & 7.77 & 7.76 \\
288.15 & 0.100 & 5.68 & 5.68 & 5.66 \\
288.15 & 0.166 & 6.13 & 6.13 & 6.07 \\
288.15 & 0.230 & 6.65 & 6.65 & 6.58 \\
288.15 & 0.299 & 7.28 & 7.28 & 7.19 \\
288.15 & 0.400 & 8.29 & 8.29 & 8.14 \\
288.15 & 0.499 & 9.32 & 9.32 & 9.21 \\
293.15 & 0.100 & 6.67 & 6.67 & 6.72 \\
293.15 & 0.166 & 7.28 & 7.28 & 7.21 \\
293.15 & 0.230 & 7.93 & 7.93 & 7.82 \\
293.15 & 0.299 & 8.67 & 8.67 & 8.54 \\
293.15 & 0.400 & 9.81 & 9.81 & 9.69 \\
293.15 & 0.499 & 11.1 & 11.1 & 11.0 \\
298.15 & 0.100 & 7.94 & 7.94 & 7.99 \\
298.15 & 0.166 & 8.62 & 8.62 & 8.58 \\
298.15 & 0.230 & 9.33 & 9.33 & 9.30 \\
298.15 & 0.299 & 10.2 & 10.2 & 10.2 \\
\hline & & & & \\
\hline
\end{tabular}




\begin{tabular}{lllll}
\hline 298.15 & 0.400 & 11.5 & 11.5 & 11.5 \\
298.15 & 0.499 & 13.2 & 13.2 & 13.1 \\
303.15 & 0.100 & 9.41 & 9.41 & 9.51 \\
303.15 & 0.166 & 10.2 & 10.2 & 10.2 \\
303.15 & 0.230 & 11.0 & 11.1 & 11.1 \\
303.15 & 0.299 & 12.1 & 12.1 & 12.1 \\
303.15 & 0.400 & 13.6 & 13.6 & 13.8 \\
303.15 & 0.499 & 15.5 & 15.5 & 15.7 \\
308.15 & 0.100 & 11.3 & 11.3 & 11.3 \\
308.15 & 0.166 & 12.1 & 12.1 & 12.2 \\
308.15 & 0.230 & 13.0 & 13.1 & 13.2 \\
308.15 & 0.299 & 14.5 & 14.4 & 14.5 \\
308.15 & 0.400 & 16.2 & 16.3 & 16.5 \\
308.15 & 0.499 & 18.4 & 18.4 & 18.8 \\
313.15 & 0.100 & 13.6 & 13.6 & 13.5 \\
313.15 & 0.166 & 14.7 & 14.6 & 14.6 \\
313.15 & 0.230 & 15.8 & 15.9 & 15.8 \\
313.15 & 0.299 & 17.5 & 17.4 & 17.4 \\
313.15 & 0.400 & 20.0 & 20.0 & 19.8 \\
313.15 & 0.499 & 22.8 & 22.8 & 22.5 \\
\hline
\end{tabular}

${ }^{a} x_{1}^{\mathrm{cal}, \mathrm{R}}, x_{1}^{\mathrm{cal}, \mathrm{J}}$ represent the calculated solubility of HA by the CNIBS/R-K and the Jouban-Acree models, respectively. And $x_{2}^{0}$ is the initial mole fraction composition of acetone in the binary solvent mixture.

${ }^{b}$ The standard uncertainty are $u(T)=0.06 \mathrm{~K}, u(p)=6 \mathrm{kPa}$, the relative standard uncertainties is $u_{\mathrm{r}}\left(x_{1}\right)=0.05, u_{\mathrm{r}}\left(x_{2}^{0}\right)=0.02$. 


\section{TABLE 6}

Parameters of the CNIBS/R-K model for the solubility of HA in binary solvent mixture.

\begin{tabular}{cccccccccc}
\hline $\begin{array}{c}\text { Bianry solvent } \\
\text { mixture }\end{array}$ & $T / \mathrm{K}$ & $B_{0}{ }^{a}$ & $B_{1}{ }^{a}$ & $B_{2}{ }^{a}$ & $B_{3}{ }^{a}$ & $B_{4}{ }^{a}$ & $R^{2 b}$ & $A R D P \%{ }^{c}$ & $10^{3} R M S D^{d}$ \\
\hline & 273.15 & -3.367 & 3.914 & 1.691 & -11.54 & 8.362 & 0.9968 & 1.257 & 1.394 \\
& 278.15 & -3.050 & 1.939 & 10.11 & -27.00 & 18.18 & 0.9942 & 1.530 & 2.013 \\
Ethanol + EA ${ }^{f}$ & 283.15 & -2.982 & 2.936 & 5.236 & -18.77 & 13.59 & 0.9959 & 1.230 & 1.821 \\
& 288.15 & -2.770 & 2.519 & 5.141 & -16.85 & 11.78 & 0.9971 & 0.965 & 1.627 \\
& 293.15 & -2.549 & 1.929 & 5.929 & -16.67 & 11.13 & 0.9944 & 1.255 & 2.412 \\
& 303.15 & -2.405 & 2.022 & 4.629 & -13.92 & 9.356 & 0.9922 & 1.397 & 3.027 \\
& 308.15 & -2.172 & 2.802 & 0.227 & -6.522 & 5.373 & 0.9944 & 1.038 & 2.929 \\
& 313.15 & -2.044 & 3.288 & -2.802 & -0.688 & 1.768 & 0.9936 & 0.988 & 3.440 \\
& 273.15 & -3.694 & 4.219 & -18.48 & 46.01 & -39.61 & 0.9982 & 0.271 & 0.135 \\
& 278.15 & -3.300 & 1.669 & -7.555 & 27.59 & -29.22 & 1.0000 & 0.044 & 0.027 \\
& 283.15 & -3.038 & -0.623 & 8.132 & -12.91 & 6.018 & 0.9999 & 0.068 & 0.049 \\
$f$ & 288.15 & -2.954 & 0.592 & 3.111 & -5.424 & 2.981 & 1.0000 & 0.007 & 0.006 \\
& 293.15 & -2.809 & 0.686 & 4.278 & -11.32 & 9.866 & 1.0000 & 0.020 & 0.020 \\
& 298.15 & -2.654 & 1.177 & 0.382 & -1.022 & 1.135 & 1.0000 & 0.008 & 0.010 \\
& 303.15 & -2.418 & -0.102 & 8.418 & -21.06 & 18.19 & 0.9998 & 0.083 & 0.118 \\
& 308.15 & -2.146 & -1.522 & 15.200 & -34.06 & 26.76 & 0.9978 & 0.307 & 0.517 \\
& 313.15 & -2.030 & -0.265 & 7.828 & -16.13 & 11.92 & 0.9992 & 0.199 & 0.407 \\
\hline
\end{tabular}

${ }^{a} B_{0}, B_{1}, B_{2}, B_{3}$ and $B_{4}$ are the parameters of the CNIBS/R-K model.

${ }^{b} R^{2}$ is the determinate coefficient.

${ }^{c} A R D P$ is the average relative deviation calculated by Eq (14).

${ }^{d} R M S D$ is the the root-mean-square deviation calculated by Eq (15).

${ }^{f}$ EA represents ethyl acetate. 


\section{TABLE 7}

Parameters of the Jouyban-Acree model for the solubility of HA in binary solvent mixture

\begin{tabular}{ccc}
\hline Parameters & ${\text { Ethanol }+\mathrm{EA}^{b}}$ & Acetone $+\mathrm{EA}^{b}$ \\
\hline$A_{0}{ }^{a}$ & -99.23 & -158.4 \\
$A_{1}{ }^{a}$ & 2123 & 4350 \\
$A_{2}{ }^{a}$ & 15.74 & 24.78 \\
$A_{3}{ }^{a}$ & -39.41 & -59.88 \\
$A_{4}{ }^{a}$ & 3049 & 2137 \\
$A_{5}{ }^{a}$ & 870.5 & 2188 \\
$A_{6}{ }^{a}$ & -3455 & -4708 \\
$A_{7}{ }^{a}$ & 2477 & 3581 \\
$A_{8}{ }^{a}$ & 5.560 & 9.226 \\
$R^{2}{ }^{3}$ & 0.9976 & 0.9992 \\
$10^{3} R M S D^{d}$ & 3.704 & 1.197 \\
\hline
\end{tabular}

${ }^{a} A_{0}, A_{1}, A_{2}, A_{3} A_{4}, A_{5}, A_{6}, A_{7}$ and $A_{8}$ are the parameters of the Jouyban-Acree model.

${ }^{b}$ EA represents ethyl acetate.

${ }^{c} R^{2}$ is the determinate coefficient.

${ }^{d} R M S D$ is the the root-mean-square deviation calculated by Eq (15). 
TABLE 8

The mixing thermodynamic properties of HA in pure solvents. ${ }^{a, b}$

\begin{tabular}{|c|c|c|c|c|}
\hline$T / K$ & $\gamma_{1}$ & $\begin{array}{c}H^{\mathrm{E}}\left(\Delta \mathrm{H}_{\text {mix }}\right) \\
\mathrm{J} \cdot \mathrm{mol}^{-1}\end{array}$ & $\begin{array}{c}\Delta G_{\text {mix }} \\
\mathrm{kJ} \cdot \mathrm{mol}^{-1}\end{array}$ & $\begin{array}{c}\Delta S_{\mathrm{mix}} \\
\mathrm{J} \cdot \mathrm{mol}^{-1} \cdot \mathrm{K}^{-1}\end{array}$ \\
\hline \multicolumn{5}{|c|}{ Ethyl acetate } \\
\hline 273.15 & 6.743 & -63.7 & -0.154 & 0.331 \\
\hline 278.15 & 6.481 & -71.4 & -0.171 & 0.358 \\
\hline 283.15 & 6.162 & -83.2 & -0.196 & 0.397 \\
\hline 288.15 & 5.878 & -94.7 & -0.219 & 0.433 \\
\hline 293.15 & 5.547 & -110 & -0.250 & 0.477 \\
\hline 298.15 & 5.166 & -131 & -0.289 & 0.532 \\
\hline 303.15 & 4.767 & -154 & -0.334 & 0.594 \\
\hline 308.15 & 4.389 & -178 & -0.381 & 0.657 \\
\hline 313.15 & 4.028 & -203 & -0.429 & 0.722 \\
\hline \multicolumn{5}{|c|}{ Ethanol } \\
\hline 273.15 & 0.8531 & 285 & -1.16 & 5.283 \\
\hline 278.15 & 0.8658 & 296 & -1.24 & 5.530 \\
\hline 283.15 & 0.8797 & 316 & -1.36 & 5.906 \\
\hline 288.15 & 0.8932 & 335 & -1.47 & 6.268 \\
\hline 293.15 & 0.9057 & 351 & -1.58 & 6.589 \\
\hline 298.15 & 0.9174 & 362 & -1.68 & 6.853 \\
\hline 303.15 & 0.9300 & 375 & -1.79 & 7.131 \\
\hline 308.15 & 0.9422 & 382 & -1.88 & 7.339 \\
\hline 313.15 & 0.9549 & 385 & -1.95 & 7.442 \\
\hline \multicolumn{5}{|c|}{ n-Butanol } \\
\hline 273.15 & 1.352 & 176 & -0.700 & 3.206 \\
\hline 278.15 & 1.362 & 184 & -0.760 & 3.392 \\
\hline 283.15 & 1.365 & 202 & -0.860 & 3.751 \\
\hline 288.15 & 1.365 & 215 & -0.951 & 4.044 \\
\hline 293.15 & 1.359 & 225 & -1.04 & 4.320 \\
\hline 298.15 & 1.350 & 227 & -1.13 & 4.562 \\
\hline 303.15 & 1.338 & 232 & -1.21 & 4.759 \\
\hline 308.15 & 1.315 & 237 & -1.30 & 4.981 \\
\hline 313.15 & 1.286 & 242 & -1.39 & 5.143 \\
\hline \multicolumn{5}{|c|}{ Isopropanol } \\
\hline 273.15 & 0.975 & 300 & -0.956 & 4.598 \\
\hline 278.15 & 1.002 & 338 & -1.07 & 5.077 \\
\hline 283.15 & 1.026 & 366 & -1.18 & 5.444 \\
\hline 288.15 & 1.048 & 393 & -1.28 & 5.791 \\
\hline 293.15 & 1.068 & 415 & -1.37 & 6.086 \\
\hline 298.15 & 1.086 & 435 & -1.46 & 6.370 \\
\hline 303.15 & 1.100 & 447 & -1.55 & 6.580 \\
\hline
\end{tabular}




\begin{tabular}{llcll}
\hline 308.15 & 1.112 & 453 & -1.62 & 6.732 \\
313.15 & 1.120 & $\begin{array}{c}456 \\
\text { Acetonitrile }\end{array}$ & -1.69 & 6.839 \\
273.15 & 5.628 & 34.8 & -0.151 & 0.681 \\
278.15 & 5.437 & 38.6 & -0.178 & 0.780 \\
283.15 & 5.198 & 43.0 & -0.209 & 0.891 \\
288.15 & 4.836 & 51.3 & -0.252 & 1.053 \\
293.15 & 4.549 & 56.1 & -0.289 & 1.176 \\
298.15 & 3.931 & 80.0 & -0.361 & 1.479 \\
303.15 & 3.208 & 127 & -0.456 & 1.925 \\
308.15 & 2.714 & 174 & -0.538 & 2.309 \\
313.15 & 2.279 & 236 & -0.628 & 2.761 \\
\hline
\end{tabular}

${ }^{a} \gamma_{1}$ is the activity coefficient of solute.

${ }^{b}$ The combined expanded uncertainties are $U \mathrm{c}\left(\Delta G_{\text {mix }}\right)=0.050 \Delta G_{\text {mix }}, U \mathrm{c}\left(\Delta S_{\text {mix }}\right)$ $=0.055 \Delta S_{m i x}(0.95$ level of confidence $)$. 


\section{TABLE 9}

The mixing thermodynamic properties of HA in binary solvent mixture \{ethanol (2) + ethyl acetate (3) $\}^{a}$

\begin{tabular}{|c|c|c|c|c|c|c|c|}
\hline$x_{2}^{0}$ & $\begin{array}{c}\Delta H_{\operatorname{mix}} \\
\mathrm{kJ} \cdot \mathrm{mol}^{-1}\end{array}$ & $\begin{array}{c}\Delta G_{\text {mix }} \\
\mathrm{kJ} \cdot \mathrm{mol}^{-1}\end{array}$ & $\begin{array}{c}\Delta S_{\text {mix }} \\
\mathrm{J} \cdot \mathrm{mol}^{-1} \cdot \mathrm{K}^{-1}\end{array}$ & $x_{2}^{0}$ & $\begin{array}{c}\Delta H_{\text {mix }} \\
\mathrm{kJ} \cdot \mathrm{mol}^{-1}\end{array}$ & $\begin{array}{c}\Delta G_{\text {mix }} \\
\mathrm{kJ} \cdot \mathrm{mol}^{-1}\end{array}$ & $\begin{array}{c}\Delta S_{\text {mix }} \\
\mathrm{J} \cdot \mathrm{mol}^{-1} \cdot \mathrm{K}^{-1}\end{array}$ \\
\hline \multicolumn{4}{|c|}{$T=273.15 \mathrm{~K}$} & \multicolumn{4}{|c|}{$T=278.15 \mathrm{~K}$} \\
\hline 0.099 & 0.169 & -0.330 & 1.68 & 0.099 & 0.167 & -0.368 & 1.78 \\
\hline 0.201 & 0.474 & -0.459 & 3.42 & 0.201 & 0.481 & -0.493 & 3.50 \\
\hline 0.299 & 0.773 & -0.610 & 5.06 & 0.299 & 0.782 & -0.653 & 5.16 \\
\hline 0.399 & 0.946 & -0.730 & 6.24 & 0.399 & 0.934 & -0.767 & 6.25 \\
\hline 0.500 & 0.973 & -0.826 & 6.15 & 0.500 & 0.971 & -0.864 & 6.17 \\
\hline 0.610 & 1.04 & -0.919 & 6.57 & 0.610 & 1.02 & -0.952 & 6.55 \\
\hline 0.700 & 1.06 & -0.982 & 6.87 & 0.700 & 1.05 & -1.029 & 6.86 \\
\hline \multicolumn{4}{|c|}{$T=283.15 \mathrm{~K}$} & \multicolumn{4}{|c|}{$T=288.15 \mathrm{~K}$} \\
\hline 0.099 & 0.166 & -0.396 & 1.84 & 0.099 & 0.165 & -0.435 & 2.08 \\
\hline 0.201 & 0.485 & -0.529 & 3.58 & 0.201 & 0.488 & -0.566 & 3.66 \\
\hline 0.299 & 0.777 & -0.681 & 5.15 & 0.299 & 0.769 & -0.710 & 5.13 \\
\hline 0.399 & 0.915 & -0.793 & 6.18 & 0.399 & 0.891 & -0.821 & 6.12 \\
\hline 0.500 & 0.958 & -0.890 & 6.12 & 0.500 & 0.942 & -0.917 & 6.07 \\
\hline 0.610 & 1.00 & -0.984 & 6.50 & 0.610 & 0.976 & -1.016 & 6.45 \\
\hline 0.700 & 1.03 & -1.067 & 6.85 & 0.700 & 1.01 & -1.101 & 6.80 \\
\hline \multicolumn{4}{|c|}{$T=293.15 \mathrm{~K}$} & \multicolumn{4}{|c|}{$T=298.15 \mathrm{~K}$} \\
\hline 0.099 & 0.161 & -0.476 & 2.17 & 0.099 & 0.153 & -0.511 & 2.23 \\
\hline 0.201 & 0.486 & -0.599 & 3.70 & 0.201 & 0.479 & -0.630 & 3.72 \\
\hline 0.299 & 0.756 & -0.738 & 5.09 & 0.299 & 0.736 & -0.761 & 5.02 \\
\hline 0.399 & 0.860 & -0.843 & 6.01 & 0.399 & 0.824 & -0.859 & 5.86 \\
\hline 0.500 & 0.919 & -0.938 & 5.97 & 0.500 & 0.888 & -0.952 & 5.84 \\
\hline 0.610 & 0.943 & -1.041 & 6.36 & 0.610 & 0.902 & -1.056 & 6.22 \\
\hline 0.700 & 0.978 & -1.130 & 6.71 & 0.700 & 0.940 & -1.150 & 6.58 \\
\hline \multicolumn{4}{|c|}{$T=303.15 \mathrm{~K}$} & \multicolumn{4}{|c|}{$T=308.15 \mathrm{~K}$} \\
\hline 0.099 & 0.140 & -0.544 & 2.26 & 0.099 & 0.122 & -0.577 & 2.27 \\
\hline 0.201 & 0.466 & -0.662 & 3.72 & 0.201 & 0.446 & -0.687 & 3.68 \\
\hline 0.299 & 0.707 & -0.778 & 4.90 & 0.299 & 0.668 & -0.787 & 4.72 \\
\hline 0.399 & 0.782 & -0.870 & 5.67 & 0.399 & 0.727 & -0.871 & 5.42 \\
\hline 0.500 & 0.849 & -0.958 & 5.67 & 0.500 & 0.796 & -0.954 & 5.40 \\
\hline 0.610 & 0.855 & -1.063 & 6.03 & 0.610 & 0.800 & -1.057 & 5.78 \\
\hline 0.700 & 0.893 & -1.162 & 6.40 & 0.700 & 0.835 & -1.160 & 6.16 \\
\hline \multicolumn{4}{|c|}{$T=313.15 \mathrm{~K}$} & & & & \\
\hline 0.099 & 0.0965 & -0.609 & 2.25 & & & & \\
\hline 0.201 & 0.413 & -0.707 & 3.58 & & & & \\
\hline 0.299 & 0.612 & -0.784 & 4.46 & & & & \\
\hline
\end{tabular}




\begin{tabular}{llll}
0.399 & 0.659 & -0.858 & 5.09 \\
0.500 & 0.719 & -0.929 & 5.01 \\
0.610 & 0.735 & -1.028 & 5.41 \\
0.700 & 0.757 & -1.133 & 5.79 \\
\hline
\end{tabular}

${ }^{a}$ The combined expanded uncertainties are $U_{\mathrm{c}}\left(\Delta G_{\text {mix }}\right)=0.050 \Delta G_{\text {mix }}, U_{\mathrm{c}}\left(\Delta S_{\text {mix }}\right)$ $=0.055 \Delta S_{\text {mix }}(0.95$ level of confidence $)$. 


\section{TABLE 10}

The mixing thermodynamic properties of HA in binary solvent mixture acetone (2) + ethyl acetate (3) $\}^{a}$

\begin{tabular}{|c|c|c|c|c|c|c|c|}
\hline$x_{2}^{0}$ & $\begin{array}{c}\Delta H_{\text {mix }} \\
\mathrm{J} \cdot \mathrm{mol}^{-1}\end{array}$ & $\begin{array}{c}\Delta G_{\text {mix }} \\
\mathrm{kJ} \cdot \mathrm{mol}^{-1}\end{array}$ & $\begin{array}{c}\Delta S_{\text {mix }} \\
\mathrm{J} \cdot \mathrm{mol}^{-1} \cdot \mathrm{K}^{-1}\end{array}$ & $x_{2}^{0}$ & $\begin{array}{c}\Delta H_{\text {mix }} \\
\mathrm{J} \cdot \mathrm{mol}^{-1}\end{array}$ & $\begin{array}{c}\Delta G_{\text {mix }} \\
\mathrm{kJ} \cdot \mathrm{mol}^{-1}\end{array}$ & $\begin{array}{c}\Delta S_{\operatorname{mix}} \\
\mathrm{J} \cdot \mathrm{mol}^{-1} \cdot \mathrm{K}^{-1}\end{array}$ \\
\hline \multicolumn{4}{|c|}{$T=273.15 \mathrm{~K}$} & \multicolumn{4}{|c|}{$T=278.15 \mathrm{~K}$} \\
\hline 0.100 & 92.7 & -0.219 & 1.14 & 0.100 & 82.0 & -0.251 & 1.20 \\
\hline 0.166 & 147 & -0.240 & 1.41 & 0.166 & 138 & -0.267 & 1.46 \\
\hline 0.230 & 181 & -0.257 & 1.60 & 0.230 & 173 & -0.283 & 1.64 \\
\hline 0.299 & 202 & -0.272 & 1.74 & 0.299 & 196 & -0.300 & 1.78 \\
\hline 0.400 & 216 & -0.301 & 1.89 & 0.400 & 215 & -0.331 & 1.96 \\
\hline 0.499 & 220 & -0.324 & 1.99 & 0.499 & 225 & -0.354 & 2.08 \\
\hline \multicolumn{4}{|c|}{$T=283.15 \mathrm{~K}$} & \multicolumn{4}{|c|}{$T=288.15 \mathrm{~K}$} \\
\hline 0.100 & 72.4 & -0.276 & 1.23 & 0.100 & 60.1 & -0.305 & 1.27 \\
\hline 0.166 & 128 & -0.292 & 1.48 & 0.166 & 115 & -0.321 & 1.51 \\
\hline 0.230 & 164 & -0.308 & 1.67 & 0.230 & 152 & -0.336 & 1.69 \\
\hline 0.299 & 189 & -0.327 & 1.82 & 0.299 & 179 & -0.354 & 1.85 \\
\hline 0.400 & 211 & -0.357 & 2.01 & 0.400 & 206 & -0.383 & 2.04 \\
\hline 0.499 & 227 & -0.383 & 2.16 & 0.499 & 229 & -0.414 & 2.23 \\
\hline \multicolumn{4}{|c|}{$T=293.15 \mathrm{~K}$} & \multicolumn{4}{|c|}{$T=298.15 \mathrm{~K}$} \\
\hline 0.100 & 45.3 & -0.335 & 1.30 & 0.100 & 26.1 & -0.369 & 1.33 \\
\hline 0.166 & 100 & -0.350 & 1.54 & 0.166 & 80.7 & -0.381 & 1.55 \\
\hline 0.230 & 137 & -0.365 & 1.71 & 0.230 & 119 & -0.393 & 1.72 \\
\hline 0.299 & 166 & -0.381 & 1.87 & 0.299 & 150 & -0.407 & 1.87 \\
\hline 0.400 & 198 & -0.410 & 2.07 & 0.400 & 186 & -0.434 & 2.08 \\
\hline 0.499 & 228 & -0.443 & 2.29 & 0.499 & 223 & -0.468 & 2.32 \\
\hline \multicolumn{4}{|c|}{$T=303.15 \mathrm{~K}$} & \multicolumn{4}{|c|}{$T=308.15 \mathrm{~K}$} \\
\hline 0.100 & 16.0 & -0.403 & 1.34 & 0.100 & 13.2 & -0.440 & 1.48 \\
\hline 0.166 & 57.5 & -0.411 & 1.54 & 0.166 & 27.6 & -0.441 & 1.52 \\
\hline 0.230 & 96.5 & -0.420 & 1.70 & 0.230 & 68.3 & -0.444 & 1.66 \\
\hline 0.299 & 129 & -0.432 & 1.85 & 0.299 & 100 & -0.454 & 1.80 \\
\hline 0.400 & 170 & -0.456 & 2.06 & 0.400 & 147 & -0.474 & 2.01 \\
\hline 0.499 & 213 & -0.490 & 2.32 & 0.499 & 197 & -0.505 & 2.28 \\
\hline \multicolumn{4}{|c|}{$T=313.15 \mathrm{~K}$} & & & & \\
\hline 0.100 & 5.12 & -0.467 & 1.53 & & & & \\
\hline 0.166 & 13.0 & -0.469 & 1.55 & & & & \\
\hline 0.230 & 27.7 & -0.472 & 1.58 & & & & \\
\hline 0.299 & 60.7 & -0.475 & 1.69 & & & & \\
\hline 0.400 & 111 & -0.482 & 1.90 & & & & \\
\hline 0.499 & 170 & -0.509 & 2.17 & & & & \\
\hline
\end{tabular}

$a$ The combined expanded uncertainties are $U_{\mathrm{c}}\left(\Delta G_{\mathrm{mix}}\right)=0.050 \Delta G_{\text {mix }}$, 
$U_{\mathrm{c}}\left(\Delta S_{\text {mix }}\right)=0.055 \Delta S_{\text {mix }}(0.95$ level of confidence $)$. 